\title{
Research on Financial Risk Monitoring of E-commerce Businesses
}

\author{
Yangjing Zhou ${ }^{1, \text { a }}$, Youqing Wan ${ }^{2, b}$ \\ ${ }^{1}$ Wuhan University of technology, School of Management, Wuhan, 43000, China \\ ${ }^{2}$ Wuhan University of technology, School of Management, Wuhan, 43000, China \\ aemail:877072541@qq.com, bemail:w13308641188@126.com
}

Keywords:E -commerce companies; Monitor financial risk; Factor analysis

\begin{abstract}
With the maturity of information technology and the degree of economic globalization, e-commerce business model has evolved from the emerging to mainstream enterprise business model, and the financial risks they face are increasingly complex and diverse. This paper try to use qualitative analysis and quantitative analysis to expand monitoring financial risks of the e-commerce companies, by factor analysis. Finally, Suning Appliance, as the main object, launched empirical research, monitor and prevent the comprehensive risk it faced.
\end{abstract}

\section{Introduction}

As the most rapid pace of development of new business models in China, e-commerce has become the main driving force to promote traditional industry business models and markets transformation. What's more, E-commerce model have a significant impact on people's way of life, and the impact of online sales model is increasingly strong to traditional retail.

Industry monitoring report based on e-commerce market shows that the amount of thee-commerce market transaction in 2014 reached 13.4 billion yuan, up 31.4\% over 2013. The largest is B2B e-commerce transactions, which size up to 10 trillion. While the retail e-commerce market got the most rapid growth, up to $49.7 \%$, which trading volume reached 2.82 billion yuan.

\section{Building Financial Risk of E-commerce Business Monitoring Model}

By identifying various risks of E-commerce business can be found a single standard is difficult to measure the risk of e-commerce business, so this paper intends to refer the dimensions of Harvard analytical framework. Using factor analysis to process the index system built on the quantitative monitoring of financial risks and accounting risks. Framework. Index System as shown in Table 1. 
Table 1 Quantitative Analysis Index System

\begin{tabular}{|c|c|c|}
\hline Level Indicators & Secondary Indicators & Variable Code \\
\hline \multirow{5}{*}{ Profitability Status } & Return on net assets ratio (\%) & $X_{1}$ \\
\hline & Return on total assets ratio(\%) & $\mathrm{X}_{2}$ \\
\hline & Main business profit margin (\%) & $\mathrm{X}_{3}$ \\
\hline & Cost margin $(\%)$ & $\mathrm{X}_{4}$ \\
\hline & Return on capital employed (\%) & $\mathrm{X}_{5}$ \\
\hline \multirow{4}{*}{ Asset quality } & Total assets turnover (times) & $\mathrm{X}_{6}$ \\
\hline & Accounts receivable turnover (times) & $\mathrm{X}_{7}$ \\
\hline & Mobile asset turnover (times) & $\mathrm{X}_{8}$ \\
\hline & Inventory turnover (times) & $\mathrm{X}_{9}$ \\
\hline \multirow{5}{*}{ Debt risk situation } & Assets and liabilities (\%) & $\mathrm{X}_{10}$ \\
\hline & Interest earned multiples & $\mathrm{X}_{11}$ \\
\hline & Quick ratio $(\%)$ & $\mathrm{X}_{12}$ \\
\hline & Cash flow debt ratio (\%) & $\mathrm{X}_{13}$ \\
\hline & Interest-bearing debt ratio (\%) & $X_{14}$ \\
\hline \multirow{5}{*}{$\begin{array}{c}\text { Operational growth } \\
\text { status }\end{array}$} & Sales (business) growth rate (\%) & $\mathrm{X}_{15}$ \\
\hline & Capital preservation rate (\%) & $\mathrm{X}_{16}$ \\
\hline & Sales profit growth rate $(\%)$ & $\mathrm{X}_{17}$ \\
\hline & Total assets growth rate $(\%)$ & $\mathrm{X}_{18}$ \\
\hline & Capital accumulation rate (\%) & $\mathrm{X}_{19}$ \\
\hline
\end{tabular}

\section{An Empirical Analysis of Monitoring Financial Risk of E-business}

\section{Select the raw data and analytical methods}

This paper select the highest level of e-commerce from the Shanghai and Shenzhen A-share listed companies as research samples. In order to obtain more standard values, the paper industry will take the e-commerce retail industry average financial indicators in "2014 Corporate Performance evaluation criteria value" included in the study sample. List of concrete samples shown in Table 2.

Table 2 Sample list

\begin{tabular}{c|c}
\hline company name & Data Code (6 ticker) \\
\hline Shenzhen Huaqiang Industry Co., Ltd. & 000062 \\
\hline Jiangsu Wujiang China Eastern Silk Market Co., Ltd. & 000301 \\
\hline Rainbow Enterprises (Holdings) Co., Ltd. & 000503 \\
\hline Suning Appliance Group Co., Ltd. & 002024 \\
\hline Zhejiang NetSun Ltd. & 002095 \\
\hline Chengdu Santai Holding Group Co., Ltd. & 002312 \\
\hline Beijing Wangfujing Department Store (Group) Co., Ltd. & 600119 \\
\hline China International Travel Service Co., Ltd. & 600640 \\
\hline
\end{tabular}

\section{Research data - Evaluation of determination}

This paper get index value of the sample from the Annual Report 2014 and disclosed information. After collected raw data and calculate the index, in order to do further analysis and research, paper uses IBM SPSS Statistic 20 software and follow each step of factor analysis requirements. 
Sample e-commerce companies explained variance table is Table 3. Table 3 shows there are five eigenvalues greater than 1 , and their cumulative contribution rate is $91.753 \%$, greater than $85 \%$, indicating that five eigenvalues have little data loss, contains a wealth of information, covering a lot of raw data. In order to achieve the desired results, select five factors to explain the effect is a better choice.

Table 3 E-commerce Companies Explained Variance Table

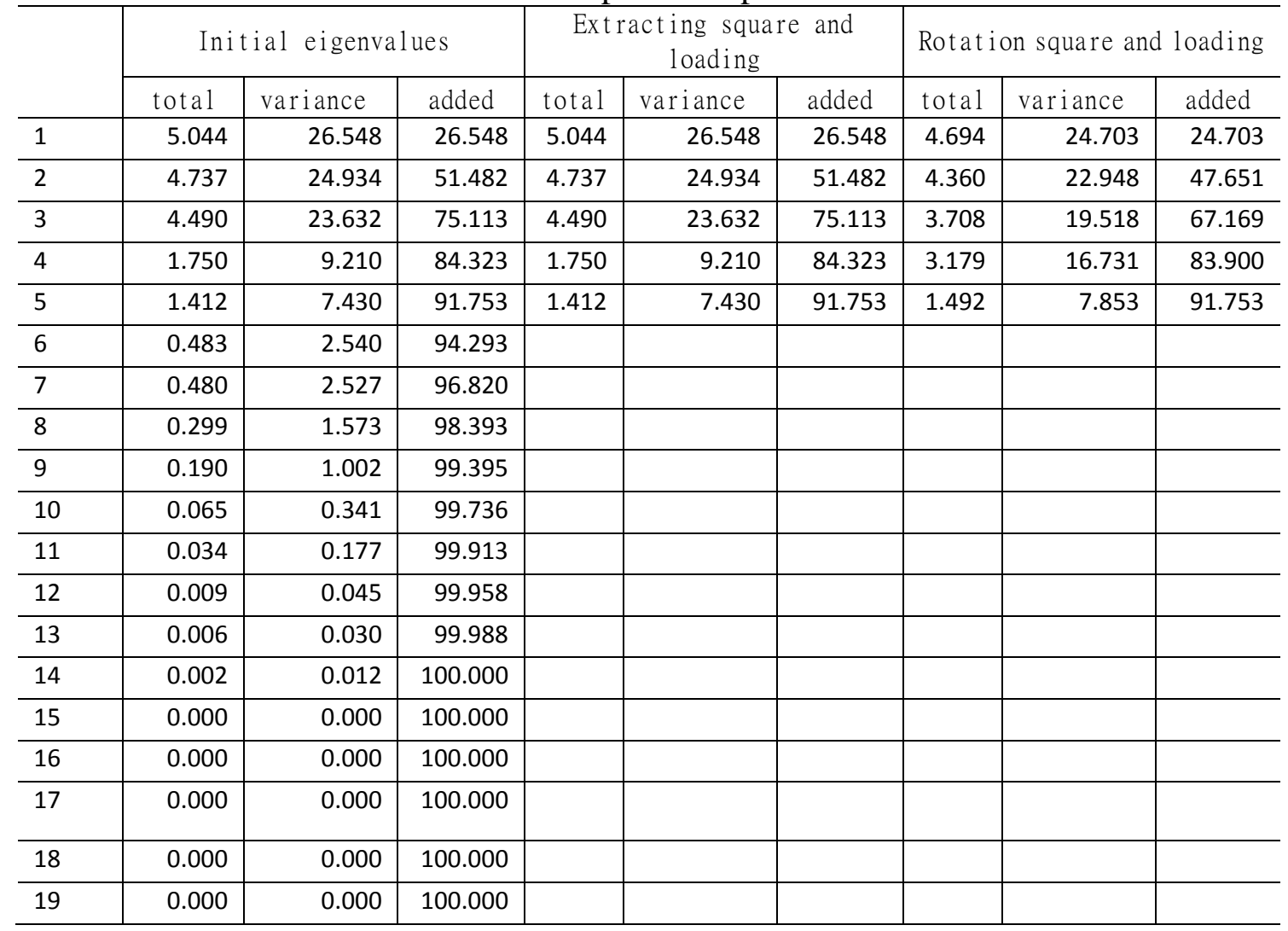

\section{Explain the meaning of each index of correlation and factor common factors}

Table 4 is a rear loading twiddle factor matrix, which shows that, after rotation. Five male factor loading tends to differentiation, compared to a more representative when not rotating, can be more fully explain the meaning of the various factors.

In factor $Z_{1}$, the maximum load is $X_{19} 、 X_{16} 、 X_{17}, X_{15}$ four indexes related to operating conditions, which reflect the growth and development potential of the enterprise, so it can be defined as the foreground risk factor. Factor $Z_{2} \operatorname{contain} X_{1} 、 X_{6} 、 X_{3} 、 X_{13}, X_{8} 、 X_{2}$, they relate to the asset and profit. With powerful external competitors, companies will face a reduction in revenue, lower profits, and the low profitability of asset status, so factor 2 can be define as earnings risk factor. FactorZ ${ }_{3}$ and variable $X_{12} 、 X_{9} 、 X_{11}, X_{14} 、 X_{10}$ relevant, these indicators jointly reflect whether a company has the ability to repay debt, so defined as debt risk factor. Factor $Z_{4}$ represent indicators $X_{4}, X_{5}$, the cost margins and return on capital. Factor $Z_{5}$ is index $X_{7}$, on behalf of accounts receivable turnover ratio. 
Table 4 sample e-commerce businesses after twiddle factor loading matrix

\begin{tabular}{c|c|c|c|c|c}
\hline \multirow{2}{*}{ variable } & \multicolumn{5}{|c}{ ingredient } \\
\cline { 2 - 6 } & 1 & 2 & 3 & 4 & 5 \\
\hline$X_{1}$ & 0.975 & 0.107 & 0.075 & 0.052 & 0.039 \\
\hline$X_{2}$ & 0.971 & 0.146 & 0.042 & 0.078 & 0.057 \\
\hline$X_{3}$ & -0.951 & 0.073 & -0.238 & -0.016 & 0.056 \\
\hline$X_{4}$ & 0.940 & -0.119 & -0.213 & 0.040 & -0.007 \\
\hline$X_{5}$ & 0.927 & -0.021 & -0.042 & -0.130 & -0.276 \\
\hline$X_{6}$ & 0.159 & 0.910 & -0.074 & 0.283 & 0.032 \\
\hline$X_{7}$ & -0.045 & 0.827 & 0.126 & -0.431 & 0.198 \\
\hline$X_{8}$ & 0.113 & 0.823 & 0.039 & 0.399 & 0.113 \\
\hline$X_{9}$ & -0.177 & 0.821 & 0.000 & -0.014 & -0.363 \\
\hline$X_{10}$ & -0.092 & 0.817 & 0.228 & -0.356 & 0.195 \\
\hline$X_{11}$ & 0.101 & 0.775 & 0.012 & 0.511 & 0.182 \\
\hline$X_{12}$ & -0.052 & -0.169 & -0.923 & 0.244 & 0.085 \\
\hline$X_{13}$ & -0.063 & -0.197 & -0.899 & -0.067 & 0.294 \\
\hline$X_{14}$ & 0.077 & 0.023 & 0.846 & -0.003 & 0.331 \\
\hline$X_{15}$ & -0.068 & -0.162 & 0.741 & -0.588 & 0.174 \\
\hline$X_{16}$ & -0.113 & -0.200 & 0.688 & -0.633 & -0.014 \\
\hline$X_{17}$ & -0.066 & 0.094 & 0.009 & 0.894 & -0.087 \\
\hline$X_{19}$ & 0.035 & -0.039 & -0.351 & 0.853 & 0.137 \\
\hline & -0.159 & 0.179 & -0.000 & 0.001 & 0.945 \\
\hline & & & & & \\
\hline
\end{tabular}

\section{Calculate the common factor formula}

After calculated, the expression of the factor shown in Equation 1-6.

$Z 1=0.159 \times X 1+0.101 \times X 2+0.113 \times X 3+0.035 \times X 4-0.066 \times X 5-0.045 X 6-0.159 \times X 7-0.092 \times X 8-0.063$ $\times \mathrm{X} 9-0.113 \times \mathrm{X} 10+0.077 \times \mathrm{X} 11-0.052 \times \mathrm{X} 12-0.177 \times \mathrm{X} 13-0.068 \times \mathrm{X} 14+0.940 \times \mathrm{X} 15+0.971 \times \mathrm{X} 16-0.951$ $\times X 17+0.927 \times X 18+0.975 \times X 19$

$\mathrm{Z} 2=0.910 \times \mathrm{X} 1+0.775 \times \mathrm{X} 2+0.823 \times \mathrm{X} 3-0.039 \times \mathrm{X} 4+0.094 \times \mathrm{X} 5+0.827 \times \mathrm{X} 6+0.179 \times \mathrm{X} 7+0.817 \times \mathrm{X} 8$ $-0.197 \times X 9-0.200 \times X 10+0.023 \times X 11-0.169 \times X 12+0.821 \times X 13-0.162 \times X 14-0.119 \times X 15+0.146 \times$ $\mathrm{X} 16+0.073 \times \mathrm{X} 17-0.021 \times \mathrm{X} 18+0.107 \times \mathrm{X} 19$

$Z 3=-0.074 \times X 1+0.012 \times X 2+0.039 \times X 3-0.351 \times X 4+0.009 \times X 5+0.126 \times X 6+0.000 \times X 7+0.228 \times X 8$ $-0.899 \times X 9+0.688 \times X 10+0.864 \times X 11-0.923 \times X 12+0.000 \times X 13+0.741 \times X 14-0.213 \times X 15+0.042 \times$ X16 $-0.238 \times X 17-0.042 \times X 18+0.075 \times X 19$

$Z 4=0.283 \times X 1+0.511 \times X 2+0.399 \times X 3+0.853 \times X 4+0.894 \times X 5-0.431 \times X 6+0.001 \times X 7-0.356 \times X 8$ $-0.067 \times X 9-0.633 \times X 10-0.003 \times X 11+0.244 \times X 12-0.014 \times X 13-0.588 \times X 14+0.040 \times X 15+0.078 \times$ X16 $-0.016 \times X 17-0.130 \times X 18+0.052 \times X 19$

$Z 5=0.032 \times X 1+0.182 \times X 2+0.113 \times X 3+0.137 \times X 4-0.087 \times X 5+0.198 \times X 6+0.945 \times X 7+0.195 \times X 8$ $+0.294 \times X 9-0.014 \times X 10+0.331 \times X 11+0.085 \times X 12-0.363 \times X 13+0.174 \times X 14-0.007 \times X 15+0.057 \times$ 
Then the contribution rate by the main factor in Table 5.4 after rotation respectively is $24.703 \%$, $22.948 \%, 19.518 \%, 16.731 \%, 7.853 \%$, can be monitored as a function of the model:

$\mathrm{F} 1=24.703 \% \times Z 1 \quad 22.948 \% \times Z 2 \quad 19.518 \% \times Z 3 \quad 16.731 \% \times Z 4 \quad 7.853 \% \times Z 5$

\section{Risk Assessment of e-commerce businesses}

Substituted the samples into the above six formula, F monitoring scores of various e-commerce enterprise financial risk, and arrange the prediction value from high to low, we can get the results in Table 5.

Table 5 Sample MonitoringScore

\begin{tabular}{|c|c|c|}
\hline Sample name & $\mathrm{F}$-measure & Ranking \\
\hline Chengdu Santai Holding Group Co., Ltd. & 887.14 & 1 \\
\hline Shenzhen Huaqiang Industry Co., Ltd. & 65.61 & 2 \\
\hline Suning Appliance Group Co., Ltd. & 62.38 & 3 \\
\hline Long Group Yangtze River Investment Industry Co., Ltd. & 41.31 & 4 \\
\hline Beijing Wangfujing Department Store (Group) Co., Ltd. & 32.62 & 5 \\
\hline Excellent value & 27.74 & 6 \\
\hline Good value & 24.87 & 7 \\
\hline Average value & 23.46 & 8 \\
\hline Lower value & 17.38 & 9 \\
\hline Jiangsu Wujiang China Eastern Silk Market Co., Ltd. & 17.01 & 10 \\
\hline China International Travel Service Co., Ltd. & 9.66 & 11 \\
\hline Poor value & 6.04 & 12 \\
\hline Pak Holding Co., Ltd. & -22.66 & 13 \\
\hline Zhejiang NetSun Ltd. & -38.07 & 14 \\
\hline Rainbow Enterprises (Holdings) Co., Ltd. & -393.17 & 15 \\
\hline
\end{tabular}

Above the table can be learned, Suning Appliance risk monitoring score is 62.38 in the 15 samples selected integrated ranked 3, and the score is higher than the industry best value. In the e-commerce industry, financial risk and accounting risk faced by the Suning Appliance is relatively small, liquidity and risk capital strand breaks will not appear in the short term. The accounting information officially arrived reliable and effective in the hands of accounting information users, corporate profitability conditions, asset quality, debt risk situation and experience growth conditions, are all in a relatively good situation. In the near-term, there are little chance of the outbreak to financial risk and accounting risk.

\section{Reference}

[1] Prasanna Gai, Sujit Kapadia.Contagion in financial networks [J].Bank of England. Quarterly Bulletin.2010,4:124.

[2] Efraim Benmelech,Nittai K. Bergman. Bankrupt and the Collateral Channel[J]. The Journal of Finance.2011,2,vol66:337-378.

[3] Xu Xu, Xu Gongwei. studybased on non-financial factors of e-commerce enterprise financial crisis[J] Friends of Accounting, 2009.08: 38-40.

[4]Yang Guang Liang Ling, Liu Luhao.supply chain financing model and risk research at the electricity supplier shopping festival environment [J] Friends of Accounting, 2015,13: 49-51.

[5] Cui Shufen,Sun Liheng. Strategic cost management under the financial model of the Internet-The balance of treasure Case[J].Accounting Communication.2015,25. 